\title{
An Examination of Waiver Usage and Injury-Related Liability Claims in Health/Fitness Facilities in Australia
}

\section{Betul Sekendiz, Robin Ammon, and Daniel P. Connaughton}

\begin{abstract}
Under Australian law, recreational service providers can use exclusion (exculpatory) clauses in their service contracts to diminish legal liability for personal injury or death due to negligence. The purpose of this study was to examine (a) the use (i.e., development and administration) of liability waivers, (b) the number of liability claims stemming from injuries, and (c) the types and locations of injuries occurring in health/fitness facilities in Queensland, Australia. The data were collected using a cross-sectional risk management survey of health/fitness facilities. Fifty-two health/fitness facility managers responded to the survey. The results indicated that waiver forms were used at all of the health/fitness facilities participating in the study. In addition, there were a total of 28 legal claims filed against the health/fitness facilities $(19 \%, n=10)$ for orthopedic injuries that were predominantly settled out of court. The findings suggest that health/fitness facilities should develop and implement comprehensive risk management programs to reduce the risk of injuries and subsequent liability claims.
\end{abstract}

Under Australian law, health/fitness facility service providers can incorporate exclusion clauses or waivers into their service agreements/contracts. These waivers preclude the signers from holding the facility and/or their employees responsible for injuries that occur during an ensuing activity. An exclusion clause, commonly known as an exculpatory clause in the United States (US), is a provision in a contract that excludes, restricts, or qualifies the rights of the parties to provide a defense to claims of breach of contract (Encyclopaedic Australian Legal Dictionary, 2014a). A waiver is where one party, by words or conduct, relinquishes a right or interest conferred by a contract (Encyclopaedic Australian Legal Dictionary, 2014b). Sometimes waivers are also referred to as releases. However, a waiver generally refers to a document signed before any damage or injury occurs, while a release is often used after an injury has occurred (Dickerson, 2010). According to Healey (1995), “The law will not determine the effectiveness of such mechanisms by a consideration of what a document is called, but rather by what the document purports to do and whether, in all the circumstances it has done" (p. 195). The courts, however, may

Sekendiz (b.sekendiz@cqu.edu.au) is with the School of Medical and Applied Sciences, Central Queensland University, Rockhampton, Queensland, Australia. Ammon is with the Division of Kinesiology and Sport Science, University of South Dakota, Vermillion, South Dakota. Connaughton is with the College of Health \& Human Performance, University of Florida, Gainesville, Florida. 
pay particular attention to the semantic difference between waiver and release in determining the effectiveness of such documents (Belna Pty Ltd v. Irwin, 2009).

In Australia, service providers including health/fitness facilities are subject to the provisions of the Australian Consumer Law (2010) $§ 60$ under Schedule 2 of the Competition and Consumer Act 2010 (Cth), which implies that all consumer contracts include a warranty that the supply of services will be rendered with due care and skill. Section 64 of the Australian Consumer Law voids any provision of a contract that purports to exclude, restrict or modify the application of this consumer warranty.

As a result of changes made to the Trade Practices Act $1974(\mathrm{Cth})(\mathrm{TPA})^{\mathrm{I}}$ as part of the tort reforms in Australian law more than a decade ago, the Trade Practices Amendment (Liability for Recreational Services) Act 2002 § 68B was incorporated in the TPA. The amendment allows contracts for certain recreational services that can limit or exclude liability for negligence and for breach of an express or implied warranty. Relevant provisions can be found in the Competition and Consumer Act (CCA) $2010 \S 139 \mathrm{~A}$, and similarly in the Civil Liability Acts of Western Australia (WA) and New South Wales (NSW). However, the CCA voids the exclusion clause if it is not limited to death, or physical or mental harm/injury to an individual. In addition, reckless misconduct by the recreational service provider must not have caused the personal injury. Section 139A (5) of the CCA describes reckless misconduct as when the service provider: (a) was aware or should reasonably have been aware of a significant risk that could result in injury to another person, and (b) engages in the conduct despite the risk and without adequate justification. Some of the other factors the courts consider when deciding the enforceability of an exclusion clause are whether the clause was (The Council of the City of Sydney v. West, 1965): (a) part of the contract, (b) appropriately worded to cover the breach that occurred, (c) reasonably brought to the attention of the other party before the contract was made, and (d) not prohibited by statute (e.g., CCA 2010 § 139A).

In recent years, two major cases in Australia demonstrated the unenforceability of exclusion clauses used by health/fitness facility operators against negligence claims. In Belna Pty. Ltd. v. Irwin (2009) the plaintiff Irwin and the defendant Belna Pty. Ltd. (hereafter "The Facility") entered into a contract when Irwin became a member of the gym. After the contract was signed, one of the fitness instructors employed by The Facility developed an exercise program for Irwin. While performing leg lunges, as prescribed by the fitness instructor's program, Irwin suffered a knee injury. As a result, Irwin sued The Facility management for breach of duty and breach of contract. At trial, the judge deemed the prescribed exercise regimen, particularly the lunges, unsuitable and beyond the plaintiff's capacity to safely perform. Accordingly, the judge ruled in favor of the plaintiff finding breach of duty of care.

At trial, The Facility claimed that under Division 5 of the Civil Liability Act 2002 (NSW) it did not owe Irwin a duty of care, either under the general law or the contract as a matter of a risk warning given to Irwin. Section 5M (1) of the Civil Liability Act 2002 (NSW) states "(1) A person (the defendant) does not owe a duty of care to another person (the plaintiff) who engages in a recreational activity to take care in respect of a risk of the activity if the risk was the subject of a risk warning to the plaintiff." Further, $\S 5 \mathrm{M}(3)$ of the Act provides that "a risk warning to a person in relation to a recreational activity is a warning that is given in a manner that is reasonably likely to result in people being warned of the risk before engaging in the recreational activity." 
The Facility argued that the risk warning provided to Irwin contained the following acknowledgment in the preexercise questionnaire she signed:

I understand that The Facility is not able to provide me with advice in regard to my medical fitness and that this information is used as a guideline to the limitations to my inability to exercise. I will not hold this club liable in any way for the injuries that may occur while I am on the premises. (Belna Pty. Ltd. v. Irwin, 2009, para. 17)

In determining the enforceability of the alleged risk warning, Toner DCJ first considered whether the services Irwin contracted for were a "recreational activity" as described in $\S 5 \mathrm{~K}$ of the Civil Liability Act 2002 (NSW). Section 5K states that a "recreational activity" is:

(a) any sport (whether the sport is an organized activity)

(b) any pursuit or activity engaged in for enjoyment, relaxation or leisure

(c) any pursuit or activity engaged in, at a place (such as a beach, park or other public open space) where people ordinarily engage in sport or in any pursuit or activity for enjoyment, relaxation or leisure.

The judge held that the exercise program undertaken by Irwin was not a "recreational activity" as defined by the Act since she undertook it to lose weight and get fit and, therefore, $§ 5 \mathrm{M}$ (1) did not apply to Irwin's claim.

The defendant appealed the lower court's decision to the New South Wales Court of Appeals and argued the trial judge erred in finding a breach of duty. An important fact in the case was that in September 2000 Irwin slipped and fell while at a shopping center and dislocated her left knee cap, which was put in a brace for several months. Before the exercise program was prepared, The Facility's fitness instructor required Irwin to complete a preexercise questionnaire. In responding to a question about "joint injuries," Irwin wrote, "Fell over in a shopping centre. Knee." When asked by the fitness instructor whether she had any problems with her knee since the accident, Irwin replied her knee was "fine" and "she had no injury with her knee" (Belna Pty. Ltd. v. Irwin, 2009, para. 22).

Irwin testified she told the fitness instructor she wanted to make sure the exercises did not damage her knee "anymore" and asked the fitness instructor whether the prescribed exercises were "okay." The appellate court affirmed the trial judge's opinion that Irwin did not admit to the fitness instructor she was still experiencing symptoms from the previous injury. Instead, Irwin wanted to make sure the prescribed exercises would not damage her knee. Furthermore, the appellate judge stressed the testimony of the plaintiff's expert witness who opined that there had been a breach of duty. The expert witness stated it is a well-known fact that after sustaining a patella dislocation a person tends to become more prone to other dislocations. Therefore, requiring a person to do a lunge exercise that stresses the musculature around the knee joint "without much training or preparatory type work" was "really exposing a person's knee joint to a high risk" (Belna Pty. Ltd. v. Irwin, 2009, para. 29). The appellate court found that once Irwin had raised the issue she had previously sustained a dislocated knee The Facility's instructor should have sought a comprehensive history to fully understand the nature of any preexisting physical or injury problems. As a result, the appellate court found The Facility negligent. 
In determining the enforceability of The Facility's risk warning defense under Division 5 of the Civil Liability Act 2002 (NSW), the appellate court judge first considered whether the services Irwin contracted for were a "recreational activity" as described in $\S 5 \mathrm{~K}$ of the Act. In regard to $\S 5 \mathrm{~K}$ (a), the appellate court applied an objective test and contended that:

... The Oxford English Dictionary contains many definitions of 'sport.' Perhaps the most apposite in the context of the statute is 'participation in activities involving physical exertion and skill.' I would add to this definition the element of participation in those activities for purposes of enjoyment, relaxation or leisure, as $5 \mathrm{~K}$ provides.

The exercise program undertaken by Irwin involved participation in activities of that kind and, according to ordinary English usage, fell within the meaning of 'sport.' (para. 13)

In relation to $\S 5 \mathrm{~K}$ (b), the appellate court applied a subjective test concluding that loss of weight and achieving physical fitness were only by-products of the exercises Irwin intended to perform. Irwin stated in the preexercise questionnaire that her short-term goal in undertaking the activities was to "enjoy life" and that her long-term goal was to lose weight and become fit (Belna Pty. Ltd. v. Irwin, 2009, para. 14). Therefore, Irwin's response on the questionnaire did not change the fact she undertook the activities for enjoyment, relaxation and leisure. Parenthetically, this decision contrasted with the trial court's decision where the district court concluded Irwin's long-term goal to lose weight and become fit excluded Ms. Irwin's exercise program from the definition of "recreational activity" under $\S 5 \mathrm{~K}$ of the Act.

As an analogy, the appellate court provided an example of "a person who runs marathons in the heat of summer does so for enjoyment, relaxation and leisure, even though she may hope to lose weight in the process" (Belna Pty Ltd v. Irwin, 2009 , para. 14). Furthermore, the appellate court opined that in respect of $\S 5 \mathrm{~K}$ (c), Irwin was engaged in exercise at a place where "people ordinarily engage in sport." As a result, the court decided the exercises Irwin had contracted for fell under the definition of recreational activity. However, as per $\S 5 \mathrm{M}(3)$ of the Act, the court ruled that Irwin's acknowledgment in the preexercise questionnaire did not warn Irwin about any risk involved in the lunge or any other exercise she undertook. Therefore, it was not considered as a risk warning under the Act.

Finally, the defendant argued that the exclusion clause in the contract excluded it from liability under $\S 5 \mathrm{~N}$ of the Civil Liability Act 2002 (NSW). Section 5N states:

(1) Despite any other written or unwritten law, a term of a contract for the supply of recreation services may exclude, restrict or modify any liability to which this Division applies that results from breach of an express or implied warranty that the services will be rendered with reasonable care and skill.

The exclusion clause used by the defendant stated:

It is my expressed interest in signing this agreement, to release the . . Fitness Centre, its Directors, Franchises, Officers, Owners, Heirs and Assigns from any and all claims for professional or general liability, which may arise as a 
result of my participation, whether fault may be attributed to myself or its employees. I understand that I am totally responsible for my own personal belongings whilst at the Centre. I also understand that each member or guest shall be liable for any property damage and/or personal injury while at the Centre. (Belna Pty. Ltd. v. Irwin, 2009, para. 38)

The appellate court highlighted several problems in the construction of the clause clustered with phrases that have an indeterminate meaning and are difficult to understand (e.g., "expressed interest," "professional or general liability," "fault . . . attributed to myself or its employees," Belna Pty. Ltd. v. Irwin, 2009, para. 39). The court also gave consideration to the semantics of the word "release" stating that a release acts to terminate any legal liability only after it occurred and that therefore the clause was not an exclusion of liability.

Accordingly, the appellate court affirmed the trial court's decision and concluded the exclusion clause was so vague as to be meaningless and could not reasonably be construed as exempting The Facility from liability as it contended.

Kovacevic v. Holland Park Holdings Pty. Ltd. (2010) is another case that demonstrates how an exclusion clause incorporated in a health/fitness facility membership agreement was held as unenforceable. The judge determined the exclusion clause in the membership agreement was not enforceable after a plaintiff suffered a fractured left ankle while participating in a group fitness class at a gymnasium. The plaintiff alleged her injury was caused by the negligence of the owner and operator of the gymnasium. The defendant gym operator relied on the gym membership contract that stated the plaintiff: (a) used the gym at her own risk, (b) would not hold the operator responsible for personal injury she suffered, and (c) waived any legal claims for any injury, loss or damage she suffered (Kovacevic v. Holland Park Holdings Pty. Ltd., 2010, para. 25).

Central to the Kovacevic defense (based on $\S 68 \mathrm{~B}$ (1) of the TPA) was the definition of "recreational services" and whether the defendant's services were covered by this definition. The defendant claimed the group fitness class was a recreational activity and therefore the exclusion clause included in the contract was appropriate.

Section 68B (2) of the TPA, defines "recreational services" as:

(a) a sporting activity or a similar leisure time pursuit; or

(b) any other activity that:

(i) involves a significant degree of physical exertion or physical risk; and

(ii) is undertaken for the purposes of recreation, enjoyment or leisure.

In this regard, the judge needed to determine if the group fitness class fell under this description. Utilizing the TPA's definition of recreational activity, the judge did not find participation in exercise classes, such as the kind the plaintiff engaged in, as a sporting activity or similar leisure time pursuit. The judge stated:

Sporting activities can cover a wide range of activities, not all of them particularly physical, but the dominant characteristic of sport is that it is competitive; the participants compete against each other, on either an individual or team basis. So far as the evidence before me reveals, the exercise classes were not in any way competitive. Nor does it strike me as something similar to a sporting activity. I am not sure what would be covered by the expression "similar leisure 
time pursuit" but although a fitness class could be described as a leisure time pursuit I would not regard it as one which was similar to a sporting activity, except perhaps to the extent that sporting activities commonly involve physical exertion. (Kovacevic v. Holland Park Holdings Pty. Ltd., 2010, para. 35)

In regard to $\S 68 \mathrm{~B}(2)(\mathrm{b})$, the judge contended the exercise class was an activity which involved a significant degree of physical exertion, but was not undertaken for the purpose of recreation, enjoyment or leisure. He stated, the exercise "... was essentially undertaken for the purpose of physical fitness, that is to say for the purpose of promoting the health and well-being of the participant." Therefore, the judge was not convinced the contract was for the supply of recreational services offered by the gym operator (Kovacevic v. Holland Park Holdings Pty. Ltd., 2010, para. 36).

The judge gave further consideration to the implications of $\S 68 \mathrm{~B}$ (1) (d) of the TPA that requires the exclusion, restriction or modification to be limited to liability for death or personal injury. Regarding the waiver the plaintiff signed in the contract, the judge stated it:

... extended expressly to all claims for articles lost, stolen or broken at the centre, or for loss or damage to any other property including automobiles and contents. The form titled "Application for Membership" included a waiver which included an acknowledgment that "my property and my person shall be at my own risk" and referred to both loss of property and personal injury. (Kovacevic v. Holland Park Holdings Pty Ltd, 2010, para. 37)

As a result, the judge ruled the waiver was void under $\S 68 \mathrm{~B}$ and the gym operator could not avoid liability for failing to exercise reasonable care for the safety of the plaintiff.

\section{Out-of-Court Settlements}

Before Australian tort reform was enacted in late 2002, debate waged between members of Parliament who claimed these reforms were crucial to preserve the Australian way of life (including sport, recreational and adventurous activities; McDonald, 2005). This thought was further supported by lobbyists from the tourism industry, amateur sporting groups, and community groups who wanted events such as kiteflying competitions and picnic days to be insured under the reforms. As a result, the definition of recreational services under the CCA and the Civil Liability Acts was expanded in the Negligence Review Report (Ipp, Sheldon, Cane \& Macintosh, 2002) to include activities which have significant inherent risks (high degree of probability) of physical harm, as well as activities which do not (Haly, 2003). Therefore, some believe the new provisions have gone too far by allowing most sport and recreational service providers to use waivers to avoid excessive personal injury claims. This was considered as a diversion of common law principles as it favored the interests of the wrongdoers over the needs and interests of the injured (Field, 2008).

McDonald (2005) contended that waivers could give recreational service providers a false sense of security and prevent, or limit, them from taking basic safety precautions against foreseeable risks of injury, thus exposing their clients to increased risks of injury. 
Data examining the trends in personal injury litigation (excluding motor and workplace accident claims) in Australian State and Territory courts before-after ${ }^{\text {II }}$ the 2002 tort reforms indicate a substantial (i.e., 60\%) decline in personal injury claims in 2004-05 (Wright, 2006). The practical implications of tort reform on negligence were also investigated by the Australian Consumer and Competition Commission (ACCC, 2005). Data were gathered from a sample of eight public liability insurers representing $71 \%$ of premiums for this class of insurance industry. Professional indemnity figures gathered from five participating insurers (representing $50 \%$ of the industry) showed premiums fell about $4 \%$ for both public liability and professional indemnity insurance. However, whether the fall in the premiums was due to increased competition among the insurance companies or due to tort reform, encouraging new insurers to enter the Australian market, is uncertain.

The report prepared by the ACCC also indicated while the frequency of public liability claims declined by over $16 \%$ of the total policies in 2001 to about $12 \%$ in 2004 , the average size/cost of out-of-court settlements showed a steady increase (over 60\%) from 1997 to 2004 mostly for personal injury and death claims (ACCC, 2005). Generally, to avoid/limit the costs (i.e., court costs, attorney fees, expert witnesses, etc.), time, and stress associated with litigation, both sides have a strong incentive to settle. However, the fact there are fewer claims may not necessarily mean there are fewer people being injured. As Field (2008) contended ". . . the injured parties have not vanished into thin air. They have simply been deprived of the ability to make a claim against those whose negligence caused their loss" (p. 82).

\section{Theoretical Background and Purpose of the Study}

Over the last two decades in Australia, there has been a growing public health concern regarding excessive body weight (Australian Institute of Health and Welfare, 2013). In 2011-12, approximately 60\% of Australian adults were classified as overweight or obese (Australian Bureau of Statistics (ABS), 2012). It has been estimated that, over the past two decades, the rate of obese and overweight people in Australia has been growing faster than any other Organization for Economic Co-operation and Development (OECD) country (Sassi, 2010). On a state-by-state basis, Queensland has the highest rate of overweight or obese adults $(64.9 \%)$ and children (27.5\%) in Australia (Department of Health, 2013). The national preventative health strategy emphasizes the importance of physical activity as a measure to reduce obesity and its' associated negative health risks (Minister for Health and Aging (MHA), 2009). Along this line, the Australian health/fitness industry has been growing faster than any other sport and recreation group with estimated revenue of over $\$ 1.2$ billion revenue in 2012 (Deloitte Access Economics, 2012). Between the end of June 2001 and 2005, the number of health/fitness clubs in Queensland increased by $61 \%$ which surpassed all other states and territories (ABS, 2009). Despite more people exercising in these facilities (ABS, 2015), recent research suggests that health/fitness facilities in Queensland demonstrated an overall lack of important risk management and safety practices (Sekendiz, 2014a; Sekendiz, Gass, Norton, \& Finch, 2014).

The principles of tort law hold a person responsible when their actions or failure to act creates an unreasonable risk that results in an injury to another. However, waivers create a potential conflict between the right to enter into contracts 
and the policy that one should be held responsible for their negligent actions that cause injury to others. Exceptions to this conflict are based on the general contract law principle that a party is not bound by a contract if the language was not clear and specific enough for the party to know, understand and appreciate the terms (Wong, 2010). The importance of utilizing properly drafted and administered waivers has been well documented (Cotten, 2013; Eickhoff-Shemek, Herbert, \& Connaughton, 2009; Miller, 2015; Young, Fields, \& Powell, 2007). Health/fitness facility managers in Australia perceived 'waivers' as the second most important risk management practice after 'insurance' (Sekendiz, 2014a). The purpose of this study was to examine (a) the use (i.e., development and administration) of liability waivers, (b) the number of liability claims stemming from injuries, and (c) types and locations of injuries occurring in health/fitness facilities in Queensland, Australia.

\section{Methods}

\section{Participants}

This study adopted the Australian Bureau Statistics (ABS, 2014) definition for health/fitness facilities which allows individuals to improve their fitness levels using available equipment and may include squash courts, swimming pools and other facilities provided their primary purpose is for the provision of fitness and exercise services. After Human Research Ethics Committee approval, every health/fitness facility in Queensland, whose contact information and e-mail address could be located using Australia's publically available online health/ fitness directories and Yellow Pages $(n=262)$, were contacted via e-mail. The managers of those facilities were invited to participate in the study. Participation was voluntary and all managers were required to read and accept the terms on the informed consent form before participating in the study. Fifty-two health/ fitness facility managers volunteered to participate in the study, representing a $20 \%$ response rate.

\section{Procedures}

The data were collected in Queensland using the Health/Fitness Industry Risk Management Questionnaire (HFRMQ; Sekendiz, 2014a). The HFRMQ (77 items under 8 scales; $\alpha=.9$ ) was developed for the Australian health/fitness industry context following a review of the literature, and expert panel review. Questionnaire items relevant to use of waivers found in "participant/membership forms" and demographic questions about the managers and their facilities were included in this study. Considering the dearth of published research on the use of waivers, legal liability claims, and sources of such claims in health/fitness facilities in Queensland, Australia, the HFRMQ was used for this study. The questionnaire items were rated on a 5-point Likert Scale ranging from 1, strongly disagree, to 5, strongly agree. The Likert scale allowed for the measurement of direction (positive or negative) and intensity (strength) of a respondent's behavior (i.e., a level of agreement rather than only yes or no). The midpoint option (i.e., "not sure") offered in the 5-point Likert scale provided important information as to 
the manager's awareness of the indicated risk management issues, and avoided a skewed pushed response that can occur in 6 point scales if the respondent does not feel confident about a certain item.

The data were collected using a staged approach. First, the online version of the HFRMQ was sent to the managers of the facilities using Survey Monkey's e-mail invitation collector. The e-mail included a cover letter with a hyperlink to the web page of the electronic questionnaire. The first page of the electronic questionnaire included an informed consent form. All of the electronic responses from the participating health/fitness facilities were kept in a password-secured database. The e-mail invitation collector was set up so neither the e-mail or Internet Protocol addresses were collected to ensure the anonymity of the research participants. The e-mail addresses of participants who had completed the survey could be tracked separately using the e-mail invitation collector. After the electronic survey was sent, two reminder e-mails were sent over the following three weeks to the facility managers who had not previously responded. The last e-mail reminder was followed by a telephone call to ask the facility managers if they had received the invitation e-mails and the reasons for their nonresponse. As a final step, facility managers who still had not responded were sent the materials, which included a cover letter, informed consent form and a prepaid return envelope for ease of return, by standard mail.

Data were analyzed using descriptive statistics (SPSS Version 20). The percentage and frequency of responses to each of the Likert items were calculated by combining the responses at the upper (positive) and lower (negative) end of the scale. The mean of the Likert-scale data were also analyzed to show the degree of agreement with each item.

\section{Results}

\section{Demographics}

The median age of the participating health/fitness facility managers was 40-yearsold and slightly more were female $(52 \%, n=27)$. Most $(60 \%, n=31)$ of the managers had been in their current position between one and five years. Thirty-seven percent $(n=11)$ had been in the health/fitness business between six and 10 years, $14 \%(n=7)$ between $11-15$ years, $17 \%(n=9)$ between one and five years, $17 \%(n$ $=9)$ between $16-20$ years, and 15\% $(n=8)$ between $21-30$ years. The respondents identified their health/fitness facilities as public $(48 \%, n=25)$, private $(48 \%, n=$ $25)$, not-for-profit $(2 \%, n=1)$ or as teaching $(2 \%, n=1)$ institutions. The average member population in $21 \%(n=11)$ of the health/fitness facilities was less than 100 , in $39 \%(n=20)$ between $101-500$, in $21 \%(n=11)$ between $501-1,000$, in $4 \%(n=2)$ between $1,001-1,500$, in $4 \%(n=2)$ between $1,501-2,000$, in $2 \%(n$ $=1)$ between 2,001-2,500, and in 2\% $(n=1)$ more than 2,500. Eight percent $(n$ $=4$ ) of the respondents "did not know" the number of members of their facility. The most popular fitness services offered were resistance training with machines (98\%, $n=51$ ), cardiovascular training (e.g., treadmills, elliptical machines; 98\%, $n=51)$, free weight training $(92 \%, n=48)$, group exercise classes $(83 \%, n=43)$, swimming pool $(29 \%, n=15)$, and racquet sports $(23 \%, n=12)$. 


\section{Use of Waivers in Health/Fitness Facilities}

In answering questions regarding the "use of waivers," all of the respondents indicated their health/fitness facilities used waivers $(100 \%, n=52$; see Table 1). A majority $(68 \%, n=35)$ of the health/fitness facility managers had their members review/update their waiver forms when their membership was renewed, but not when a member started participating in a new type of activity $(52 \%, n=27)$. While most $(72 \%, n=37)$ of the health/fitness managers obtained legal advice when developing their waivers and membership forms, 23\% $(n=12)$ of the respondents were "not sure" if legal advice was obtained when doing so.

\section{Use of Preactivity Screening Procedures in Health/Fitness Facilities}

Most of the health/fitness facility managers reported that there were preactivity screening procedures $(92 \%, n=48)$ and medical referral systems $(98 \%, n=51)$ in place at their facilities (see Table 1).

\section{Legal Liability Claims}

When the health/fitness facility managers were asked if their facility had ever been sued by a participant who sustained injuries at their facility, of the facilities that had been sued $(19 \%, n=10)$ by a participant, $20 \%(n=2)$ had been sued once,

\section{Table 1 Use of Participant/Membership Forms in Health/Fitness Facilities}

\begin{tabular}{lcccc}
\hline & $n$ & $\boldsymbol{M}^{*}$ & SD & SE \\
\hline $\begin{array}{l}\text { All participants are required to sign a waiver } \\
\text { form. }\end{array}$ & 52 & 4.67 & 0.47 & 0.07 \\
$\begin{array}{l}\text { Waiver forms are updated when a membership is } \\
\text { renewed. }\end{array}$ & 52 & 3.75 & 1.22 & 0.17 \\
$\begin{array}{l}\text { Waiver forms are updated when a member starts } \\
\text { participating in a new type of activity. }\end{array}$ & 52 & 2.96 & 1.24 & 0.17 \\
$\begin{array}{l}\text { Legal advice was obtained while developing } \\
\text { contracts such as waiver forms and membership } \\
\text { forms. }\end{array}$ & 52 & 4.02 & 0.98 & 0.14 \\
$\begin{array}{l}\text { All participants must undertake preactivity } \\
\text { screening procedures. }\end{array}$ & 52 & 4.35 & 0.84 & 0.12 \\
$\begin{array}{l}\text { If a participant is identified as having a medical } \\
\text { concern as a result of preactivity screening that } \\
\text { person is required to consult with a qualified } \\
\text { healthcare provider. }\end{array}$ & 52 & 4.52 & 0.54 & 0.08 \\
\hline
\end{tabular}

Note. The HFRMQ items were on a 5-point Likert scale from Strongly Disagree (1) to Strongly Agree (5). * The closer the mean value to 5, the stronger the agreement with the particular item.

Abbreviations: $n=$ Number; $M=$ Mean; $S D=$ Standard deviation; $S E=$ Standard error of mean. 
$50 \%(n=5)$ had been sued two times, $20 \%(n=2)$ had been sued three times, and $10 \%(n=1)$ had been sued five times indicating a total of 23 lawsuits. When these health/fitness facility managers were asked how many of these lawsuits were settled out of court, $20 \%(n=2)$ reported one, $40 \%(n=4)$ reported two, $10 \%$ $(n=1)$ reported three, $20 \%(n=2)$ reported four, and $10 \%(n=1)$ reported six out-of-court settlements indicating a total of 27 out-of-court settlements which exceeded the number $(n=23)$ of the reported lawsuits.

Of the 23 lawsuits only one went to trial, while 22 were settled after a suit was filed. Five of the managers reported more out-of-court settlements than the number of lawsuits they initially reported, which may indicate that five legal claims were settled before court action started (see Figure 1). On the whole, there were a total of 28 legal claims against 19\% of the health/fitness facilities.

\section{Sources of Legal Liability Claims}

The source of the lawsuits brought against the health/fitness facilities was determined by asking the facility managers the number, location and type of injuries sustained in their facilities, and the type of injuries resulting in legal claims (see Table 2).

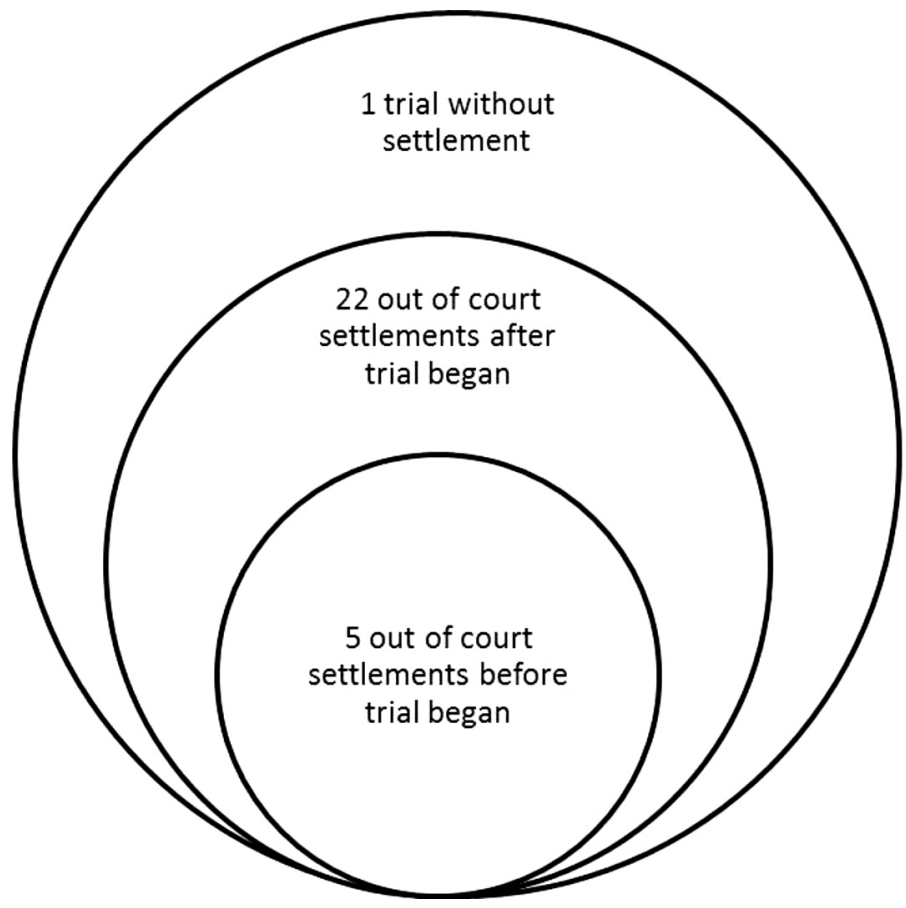

Figure 1 - Results of the reported liability claims against health/fitness facilities. 
Table 2 Number, Type, and Location of Injuries, and Injuries Resulting in Legal Claims Against Health/Fitness Facilities

\begin{tabular}{|c|c|c|}
\hline \multirow[b]{2}{*}{ Sources of legal claims } & \multicolumn{2}{|c|}{ Facilities } \\
\hline & $n$ & $\%$ \\
\hline \multicolumn{3}{|l|}{ Number of injuries } \\
\hline $1-3$ & 18 & 35 \\
\hline $4-6$ & 14 & 27 \\
\hline $7-9$ & 4 & 8 \\
\hline$>10$ & 5 & 10 \\
\hline 0 & 11 & 19 \\
\hline \multicolumn{3}{|l|}{ Types of injuries } \\
\hline Sprains/strains & 44 & 85 \\
\hline Seizure & 1 & 2 \\
\hline Slips, trips, falls & 1 & 2 \\
\hline Treadmill injuries & 1 & 2 \\
\hline Contusions & 1 & 2 \\
\hline Hip fracture & 1 & 2 \\
\hline \multicolumn{3}{|l|}{ Location of injuries } \\
\hline Weight training & 21 & 40 \\
\hline Group exercise & 11 & 21 \\
\hline Outside the facility & 1 & 2 \\
\hline Basketball & 1 & 2 \\
\hline Swimming pool/aquatics & 3 & 6 \\
\hline Personal training & 2 & 4 \\
\hline \multicolumn{3}{|c|}{ Injuries resulting in legal claims } \\
\hline Orthopedic injuries & 5 & 50 \\
\hline Sprains/strains & 5 & 50 \\
\hline
\end{tabular}

Number, Type, and Location of Injuries. In the 12 months before the study, $35 \%$ $(n=18)$ of health/fitness facilities reported between one and three injuries, $27 \%(n$ $=14)$ reported between four and six, $8 \%(n=4)$ reported between seven and nine injuries, and $10 \%(n=5)$ reported more than 10 . Nineteen percent of the health/ fitness facility managers reported that no injuries occurred in the 12 months before the current study. When compared with the 12 months before the study, $46 \%$ ( $n=$ $24)$ of the health/fitness facilities had a similar number of injuries, $4 \%(n=2)$ had more injuries, while $15 \%(n=8)$ had fewer injuries. Nineteen percent $(n=10)$ of the health/fitness facility managers were "not sure' how the number of injuries compared to the previous 12 -month period. 
The respondents reported sprains/strains $(85 \%, n=44)$ as the most common type of injuries that occurred in their facilities. Other types of injuries that occurred in the health/fitness facilities were "slips, trips and falls" $(2 \%, n=1)$, "sprains/ strains, grazes from falling off a treadmill" ( $2 \%, n=1)$, "contusion" $(2 \%, n=1)$, a "seizure" $(2 \%, n=1)$ and a "hip fracture" sustained when an elderly male lost his balance and fell during a personal training session $(2 \%, n=1)$.

The location with the highest number of reported injuries in the health/fitness facilities was the weight training area $(40 \%, n=21)$. This was followed by the group exercise area $(21 \%, n=11)$ and cardio area $(12 \%, n=6)$. Other areas of reported injuries included "slippery tiles outside the facility" $(2 \%, n=1)$, "basketball area" $(2 \%, n=1)$, "swimming pool" $(6 \%, n=3)$, and "personal training" $(4 \%, n=2)$.

Type of Injuries Resulting in Legal Claims. Health/fitness facility managers reported orthopedic injuries $(50 \%, n=5)$ and sprains/strains $(50 \%, n=5)$ as the major types of injuries resulting in litigation. For example, one "back injury" was allegedly caused by a "back-supported leg machine exercise" prescribed by a personal trainer.

\section{Discussion}

The results of this study suggest that while all of the health/fitness facilities in Queensland required their participants to sign a waiver, 23\% $(n=12)$ of the facility managers were "not sure" if legal advice was obtained in developing their waiver forms. Many health/fitness facility managers also disagreed $(19 \%, n=10)$ or were "not sure" $(14 \%, n=7)$ that they had their members review/update their waiver forms when their membership was renewed. The enforceability of waivers is complicated and depends on the defendants satisfying various elements, including whether the exclusion clause was (a) part of the contract, (b) was appropriately worded to cover the breach that occurred, (c) was reasonably communicated to the potential member before the contract was signed, and (d) was not prohibited by statute. The provisions of the CCA also require the exclusion clauses incorporated into contracts by recreational service providers be limited to liability for death or personal injury relevant to the activities that they offer. Therefore, it is important health/fitness facility managers obtain legal advice while drafting or revising waivers and membership forms. In addition, health/fitness facility managers should make sure their waivers are brought to the attention of the participants when they join or renew their memberships. Participants should be encouraged to not only read waivers but to also ask any questions they may have before signing.

While it was not one of the aims of this study to analyze the effectiveness of exclusion clauses or waivers used by health/fitness service providers, such documents have been challenged in the courts regarding whether the fitness services contracted for fell within the definition of "recreational services" under the CCA. However, as Villa (2009) contends, legislation governing the service of recreational activities is problematic and open to an array of different interpretations. Section 139A (2) of the CCA defines "recreational services" as (a) a sporting activity or a similar leisure time pursuit; or (b) any other activity that (i) involves a significant degree of physical exertion or physical risk and (ii) is undertaken for the purposes of recreation, enjoyment, or leisure. In Kovacevic v. Holland Park Holdings Pty. 
Ltd. (2010) the court held the contract in the case was not a contract for the supply of recreational services by the gym operator as the exercise was essentially undertaken by the plaintiff to promote health and well-being; thus voiding the waiver. This contradicted the decision of the appellate judge in Belna Pty. Ltd. v. Irwin (2009) who upheld the use of the waiver as a defense in regard to information the plaintiff provided in the preexercise questionnaire. Such information indicated that her short term/main goal was to enjoy life, and losing weight and becoming fit were only her long-term goals/outcomes of the exercises she contracted for. However, the appellate judge did not mention if the subsections of 139A (2) of the CCA were exhaustive. Therefore, had the plaintiff indicated on the preexercise questionnaire that her short term goal was to lose weight and become fit, it is plausible that the judge's decision on the applicability of the waiver could have been negative.

The telephone follow-ups made during the data collection process indicated that some of the health/fitness club managers wanted to be excluded from the study because they were "helping clients with weight loss" and, therefore, believed that they "should not be considered as traditional health/fitness facilities." In recent years, more people have been using health/fitness facilities to improve their health, fitness, well-being and weight-loss (ABS, 2007). Health/fitness facilities have also been working with allied health professionals to offer more specifically-designed programs that target older people with chronic health conditions (Exercise is Medicine Australia, 2014). In 2012, the largest increase (27\%) in the number of clients in the Australian health/fitness industry occurred in the 45-54 year age group and $11 \%$ of these clients were referrals by allied health professionals (Fitness Australia, 2012). The American College of Sports Medicine's (ACSM) top 10 fitness trends worldwide for 2014 included health and fitness programs for older adults (Thompson, 2013). In this regard, health/fitness service providers should expect more higher risk clients which are common in an overweight and aging population (Thompson et al., 2007).

The findings of this study indicated that the vast majority $(92 \%, n=48)$ of the health/fitness facilities used preexercise screening procedures and had medical referral systems in place $(98 \%, n=51)$. These are important risk management practices in demonstrating a health/fitness facility used reasonable care to minimize the risk of injuries to participants (Eickhoff-Shemek, Herbert, \& Connaughton, 2009; Sekendiz, 2014b; Tharrett \& Peterson, 2012). On the other hand, improperly conducted preexercise screenings and/or medical referral systems can be used against a defendant.

Published recommendations by the health/fitness industry's major professional organizations highlight the importance of preactivity screening procedures in health/fitness programs (Sekendiz et al., 2014; Tharrett \& Peterson, 2012). As the decision in Belna Pty. Ltd. v. Irwin (2009) illustrates, the mere use of a preexercise questionnaire before prescribing any exercise program may not be effective in satisfying the duty of care owed to a participant, unless a comprehensive health history was gathered to fully understand the nature of any preexisting condition or injury that was revealed in a preactivity screening. Therefore, in an effort to prescribe appropriate and reasonably safe exercise programs, and to minimize the risk of injuries and adverse medical outcomes, health/fitness facilities should properly conduct preexercise screening procedures and have a medical referral system in place. This is particularly important since exclusion clauses or waivers may not 
be a valid defense for breaches of contractual warranties of fitness programs that are engaged in, as a main purpose, for the promotion of health, fitness and wellbeing. In addition to preactivity screening, medical referral systems, and the use of waivers, a comprehensive risk management plan for reducing injuries, deaths, and liability in health/fitness facilities should also address health/fitness assessment and prescription, instruction and supervision, warnings, equipment/facility inspection and maintenance, medical emergency action plans, and documentation (Eickhoff-Shemek, Herbert, \& Connaughton, 2009; Tharrett \& Peterson, 2012).

The respondents reported a total of 28 lawsuits that were filed against their facilities and the vast majority $(96 \%)$ were settled out of court. Of the reported lawsuits, one (3\%) went to trial without settlement, $22(79 \%)$ were settled after a trial began, and five (18\%) were settled before a trial began. From one perspective, the higher number of out-of-court settlements may be due to the strong incentive to avoid the high costs of going to trial (e.g., court costs, attorney and expert witness fees, etc.). From another perspective, the higher number of settlements may have been due to the restrictions placed on the recovery of legal compensation claims following the 2002 tort reforms in Australia. For example, in Queensland (Qld), amendments to the Personal Injuries Proceedings Act 2002 (Qld), encourage settling claims at early stages and restrict injured plaintiffs from recovering costs involving awards less than $\$ 50,000$ (AU). Furthermore, defendants may seek a settlement to avoid the negative publicity often associated with litigation. On the basis of these assumptions, the results of this study suggest that fewer liability cases does not mean there are less injuries due to the negligence of health/fitness service providers. In fact, the findings of this study indicated that there were approximately four injuries per facility in the 12 months before this study. In $46 \%(n=24)$ of the facilities the number of injuries remained the same, while $19 \%(n=10)$ of the facility managers were "not sure" how the current number of injuries compared with the previous 12 months. A possible reason for these regularly occurring injuries and a lack of awareness of the facility managers about the injures in their facilities, could be a result of their not being actively involved in the risk management aspect of their facility and/or a lack of accident/injury reporting which is an important risk management strategy in assessing risks and reviewing the effectiveness of current risk management practices.

Several limitations to this study exist. These include, but are not limited to, data were only collected in Queensland which limits the generalizability of the results. The demographic profile of the health/fitness facilities and managers who participated in this study was, however, representative of the nationwide profile of the fitness industry (Fitness Australia, 2009). In addition, the response rate was suboptimal. The lower response rate may be related to liability concerns of the facility managers and/or perceived legal consequences for revealing information regarding legal issues.

\section{Conclusion}

The findings of this exploratory study have implications for health/fitness service providers in Australia. First, health/fitness facility managers should obtain legal advice when drafting or revising membership forms and waivers to ensure that the 
exclusion clause is (a) part of the contract, (b) appropriately and clearly worded, (c) reasonably communicated to potential and renewing member, and (d) not prohibited by statute. Second, waivers must not be treated as the only, or most important, risk management practice to reduce injuries, deaths, and subsequent liability claims. Comprehensive risk management practices should be implemented and include, but not be limited to, preactivity screening procedures; medical referral systems; proper health/fitness assessment, prescription, instruction and supervision; equipment/ facility maintenance and inspection; warnings; emergency action planning; and injury/incident documentation (Eickhoff-Shemek, Herbert, \& Connaughton, 2009; Tharrett \& Peterson, 2012). Health/fitness facility managers should also actively monitor and review their risk management program to determine if it is meeting its goals and objectives (Ammon, 2013; Standards Australia, 2009). Finally, additional research in this area as well as a national study is warranted.

\section{Notes}

I Effective January 1, 2011, the TPA and the relevant Fair Trading Acts and regulations in States and Territories were consolidated into the Competition and Consumer Act 2010 (CCA) Schedule 2 which sets out a uniform Australian Consumer Law.

II The analysis excluded from both the "before" and "after" calculation data for a year in which there was an evident "spate" increase in claims preceding the implementation of reforms. In summary, the periods compared, by jurisdiction are as follows: ACT "before" (1995-2002), "after" (2003-2005); New South Wales "before" (1996-2000), "after" (2003-2005) (2001, 2002 excluded); Northern Territory "before" (1995-2002), "after" (2004-2005) (2003 excluded); Queensland "before" (1995/6-2001/2), "after" (2002/3-2004/5); South Australia "before" (1995-2001), "after" (2003-2005) (2002 excluded); Tasmania "before" (1995/6-2001/2), "after" (2002/3-2004/5); Victoria "before" (1996-2001), "after" (2004-2005) (2002 and 2003 excluded); and Western Australia "before" (1996-2002), "after" (2003-2005).

\section{References}

Ammon, R. (2013). Risk management process. In D.J. Cotton \& J.T. Wolohan (Eds.), Law for recreation and sport managers (pp. 278-288). Dubuque, IA: Kendall Hunt.

Australian Bureau of Statistics (ABS). (2009). 4156.0.55.001 - Perspectives on Sport, May 2009: Health and Fitness Centres and Gymnasia (Feature Article 2). Retrieved from http://www.abs.gov.au

Australian Bureau of Statistics (ABS). (2012). 4364.0.55.001 - Australian Health Survey: First Results, 2011-12. Retrieved from http://www.abs.gov.au

Australian Bureau of Statistics (ABS). (2014). 4902.0 - Australian Culture and Leisure Classifications (3rd Ed.). Retrieved from http://www.abs.gov.au

Australian Bureau of Statistics (ABS). (2015). 4177.0 - Participation in Sports and Physical Recreation, 2013-14. Retrieved from http://www.abs.gov.au

Australian Consumer and Competition Commission (ACCC). (2005). Public liability and professional indemnity insurance: Fifth monitoring report. Dickson, ACT: ACCC.

Australian Consumer Law 2010 (Cth).

Australian Institute of Health and Welfare (AIHW). (2013). Overweight and Obesity. Retrieved from http://www.aihw.gov.au

Belna Pty. Ltd. v. Irwin, NSWCA 46 (2009).

Competition and Consumer Act 2010 (Cth). 
Cotten, D.J. (2013). Waivers and releases. In D.J. Cotton \& J.T. Wolohan (Eds.), Law for recreation and sport managers (pp. 107-116). Dubuque, IA: Kendall Hunt.

Deloitte Access Economics. (2012). Fitness Industry Workforce Report 2010 - 2020, Report for Fitness Australia. Retrieved from http://www.fitness.org.au

Department of Health. (2013). Measured obesity in Queensland 2011-12. Brisbane: Department of Health, Queensland Government. Retrieved from http://www.health.qld.gov.au

Dickerson, D. (2010). Sign and release? Using waivers and releases as risk-management tools. Campus Activities Programming. Retrieved from http://ssrn.com/abstract=1534619.

Eickhoff-Shemek, J.M., Herbert, D.L., \& Connaughton, D.P. (2009). Risk management for health/fitness professionals: Legal issues and strategies. Baltimore, MD: Lippincott, Williams \& Wilkins.

Encyclopaedic Australian Legal Dictionary. (2014a). Exclusion clause. Retrieved from http://www.lexisnexis.com/au

Encyclopaedic Australian Legal Dictionary. (2014b). Waiver. Retrieved from http://www. lexisnexis.com/au

Exercise is Medicine Australia. (2014). Exercise is Medicine Australia. Retrieved from http://exerciseismedicine.org.au

Field, A. (2008). 'There must be a better way': Personal injury compensation since the crisis in insurance. Deakin Law Review, 13(1), 67-98. doi:10.21153/dlr2008vol13no1art153

Fitness Australia. (2009). Fitness Industry Profile Report 2008. Retrieved from https:// fitness.org.au

Fitness Australia. (2012). The Australian Fitness Industry Report 2012. Retrieved from https://fitness.org.au

Haly, A. (2003). The Trade Practices Amendment (Liability for Recreational Services) Act 2002: Complete solution or deficient response? Competition \& Consumer Law Journal, 11, 1-18.

Healey, D. (1995). Disclaimers, exclusion clauses, waivers and liability release forms in sport: Can they succeed in limiting liability? In M. Fewell (Ed.), Sport law: A practical guide. Sydney, Australia: Law Book Company.

Ipp, D. A., Sheldon, P. C., Cane, P. \& Macintosh, I. (2002) Review of the law of negligence: Final report. Canberra, Australia: Commonwealth of Australia.

Kovacevic v. Holland Park Holdings Pty Ltd., QDC 279 (2010).

McDonald, B. (2005). Legislative intervention in the law of negligence: The common law, statutory interpretation and tort reform in Australia. The Sydney Law Review, 27, 443-482.

Miller, J.J. (2015). Gross negligence, inherent risks, assumption of risks: Using waivers to protect fitness clubs. Journal of Physical Education, Recreation \& Dance, 86(4), 54-56. doi:10.1080/07303084.2015.1009810

Minister for Health and Aging (MHA). (2009). Australia: The healthiest country by 2020, national preventative health strategy. Retrieved from http://www.preventativehealth. org.au

Personal Injuries Proceedings Act 2002 (Qld).

Sassi, F. (2010). Obesity and the economics of prevention: Fit not fat. Retrieved from http:// www.oecdbookshop.org doi:10.4337/9781849808620

Sekendiz, B. (2014a). Implementation and perception of risk management practices in health/ fitness facilities. International Journal of Business Continuity and Risk Management, 5(3), 165-183. doi:10.1504/IJBCRM.2014.066148

Sekendiz, B. (2014b). Personal trainers giving tough love: Risks and consequences. ACSM's Health \& Fitness Journal, 18(3), 8-11. doi:10.1249/FIT.0000000000000032

Sekendiz, B., Gass, G., Norton, K., \& Finch, C.F. (2014). Cardiac emergency preparedness in health/fitness facilities in Australia. The Physician and Sportsmedicine, 42(4), 14-19. doi:10.3810/psm.2014.11.2087 
Standards Australia. (2009). AS/NZS ISO31000:2009: Risk management-Principles and guidelines. North Sydney, NSW.

Tharrett, S.J., \& Peterson, J.A. (Eds.). (2012). ACSM's health and fitness facility standards and guidelines (4th ed.). Champaign, IL: Human Kinetics.

The Council of the City of Sydney v. West, 114 CLR 48 (1965).

Thompson, P.D., Franklin, B.A., Balady, G.J., Blair, S.N., Corrado, D., Estes, N.A.M., . . . Costa, F. (2007). Exercise and acute cardiovascular events: Placing the risks into perspective: A scientific statement from the American Heart Association Council on Nutrition, Physical Activity, and Metabolism and the Council on Clinical Cardiology. Circulation, 115(17), 2358-2368. doi:10.1161/CIRCULATIONAHA.107.181485

Thompson, W.R. (2013). Now trending: Worldwide survey of fitness trends for 2014. ACSM's Health \& Fitness Journal, 17(6), 10-20.

Trade Practices Act 1974 (Cth).

Trade Practices Amendment (Liability for Recreational Services) Act 2002 (Cth).

Villa, D. (2009). Liability for personal injury arising from the supply of recreational services. Australian and New Zealand Sports Law Journal, 4(1), 55-81.

Wong, G.M. (2010). Essentials of Sports Law (4th ed.). Santa Barbara, CA: ABC-CLIO.

Wright, E.W. (2006). National trends in personal injury litigation: Before and after Ipp. Torts Law Journal, 14(3), 233-267.

Young, S.J., Fields, S.K., \& Powell, G.M. (2007). Risk perceptions versus realities in campus recreational programs. Recreational Sports Journal, 31(2), 131-145. 